\title{
Response to: systematic review of dietary, nutritional, and physical activity interventions for the prevention of prostate cancer progression and mortality by Hackshaw-McGeagh and Colleagues
}

\author{
Wendy Demark-Wahnefried ${ }^{1}$ (D)
}

Received: 10 October 2016/ Accepted: 17 June 2017/Published online: 24 June 2017

(C) Springer International Publishing AG 2017

We applaud the systematic review of Hackshaw-McGeagh et al. [1] on dietary, nutritional, and physical activity interventions for the prevention of prostate cancer progression and mortality. The paper makes a notable contribution to the literature and is thorough, well designed, and well written. However, there is one correction that we would like to bring to the attention of the authors. Though rated highly according to the vast majority of criteria, our randomized controlled trial (RCT) was cited as being ineffectively blinded either with respect to study participants or personnel. While true that we were unable to blind our study participants to either the low fat diet or flaxseed supplementation, the two experimental conditions in our NIH-funded presurgical trial among 161 men who were awaiting prostatectomy, our study staff were indeed blinded $[2,3]$. The primary endpoint for this trial was proliferation rate in the tumor, for which the two study pathologists, each blinded to arm assignment, rendered independent assessments. Moreover, all biochemical assays, whether for serum levels of prostate specific antigen, testosterone, sex hormone binding globulin, insulinlike growth factor (IGF)-1, IGF binding protein-3, c-reactive protein, or total and LDL-cholesterol, or for the lipid composition of prostatic tissue or erythrocyte membranes, or the urinary and seminal fluid lignans were all performed by laboratory personnel who were blinded with regard to arm assignment. Thus, while ours is a single-blinded investigation and is subject to some bias, the threat is relatively small. Again, we appreciate this well done systematic review, but thought we needed to bring this misclassification to the attention of both the authors and the readers.

Thank you.

\section{References}

1. Hackshaw-McGeagh LE, Perry RE, Leach VA, Qandil S, Jeffreys M, Martin RM, Lane JA (2015) A systematic review of dietary, nutritional, and physical activity interventions for the prevention of prostate cancer progression and mortality. Cancer Causes Control 26(11):1521-1550

2. Demark-Wahnefried W, George SL, Switzer BR, Snyder DC, Madden JF, Polascik TJ, Ruffin MT et al (2008) Overcoming challenges in designing and implementing a phase II randomized controlled trial using a presurgical model to test a dietary intervention in prostate cancer. Clin Trials 5(3):262-272

3. Demark-Wahnefried W, Polascik TJ, George SL, Switzer BR, Madden JF, Ruffin MT, Snyder DC et al (2008) Flaxseed supplementation (not dietary fat restriction) reduces prostate cancer proliferation rates in men presurgery. Cancer Epidemiol Biomark Prev 17(12):3577-3587
Wendy Demark-Wahnefried

demark@uab.edu

1 Department of Nutrition Sciences, University of Alabama at Birmingham, Birmingham, USA 